Revised Manuscript Number BRB-D-16-00156

\title{
Microtubules in health and degenerative disease of the nervous system
}

\section{Andrew J. Matamoros and Peter W. Baas}

Department of Neurobiology and Anatomy

Drexel University College of Medicine

2900 Queen Lane

Philadelphia, PA 19129

Address Correspondence to:

Peter W. Baas, Ph.D.

Department of Neurobiology and Anatomy

Drexel University College of Medicine

2900 Queen Lane

Philadelphia, PA 19129

Phone: 215-991-8291

Fax: 215-843-9082

Email: pbaas@drexelmed.edu

Running Title: Microtubules in the nervous system

Key words: microtubule, neuron, axon, dendrite, katanin, spastin, fidgetin, dynein, kinesin, neurodegeneration, Alzheimer's disease, tau, tauopathy, microtubule-associated proteins, molecular motor proteins, axonal transport, CAMSAP, tubulin, tubulin code, microtubule stability, +tips 


\section{Abstract}

Microtubules are essential for the development and maintenance of axons and dendrites throughout the life of the neuron, and are vulnerable to degradation and disorganization in a variety of neurodegenerative diseases. Microtubules, polymers of tubulin heterodimers, are intrinsically polar structures with a plus end favored for assembly and disassembly and a minus end less favored for these dynamics. In the axon, microtubules are nearly uniformly oriented with plus ends out, whereas in dendrites, microtubules have mixed orientations. Microtubules in developing neurons typically have a stable domain toward the minus end and a labile domain toward the plus end. This domain structure becomes more complex during neuronal maturation when especially stable patches of polyaminated tubulin become more prominent within the microtubule. Microtubules are the substrates for molecular motor proteins that transport cargoes toward the plus or minus end of the microtubule, with motordriven forces also responsible for organizing microtubules into their distinctive polarity patterns in axons and dendrites. A vast array of microtubule-regulatory proteins impart direct and indirect changes upon the microtubule arrays of the neuron, and these include microtubule-severing proteins as well as proteins responsible for the stability properties of the microtubules. During neurodegenerative diseases, microtubule mass is commonly diminished, and the potential exists for corruption of the microtubule polarity patterns and microtubule-mediated transport. These ill effects may be a primary causative factor in the disease or may be secondary effects, but regardless, therapeutics capable of correcting these microtubule abnormalities have great potential to improve the status of the degenerating nervous system. 


\section{Introduction}

The microtubule arrays of axons and dendrites provide a structural backbone that allows them to acquire and maintain their specialized morphologies. In addition to acting as structural elements, microtubules are long-distance railways for proteins and organelles to be actively transported in both directions within axons and dendrites. Microtubules are crucial for early developmental stages of the neuron, such as migration of the soma and the navigation of the growth cone at the tip of the elongating axon. Microtubules are also important throughout the life of the neuron, for it to maintain its proper morphology, to enable axonal and dendritic transport, and to accommodate morphological changes such as alterations in dendritic shape that may correspond with cognitive plasticity, even in old age. Proper functioning of microtubules and their assortment of interacting and regulatory proteins as well as regulatory pathways is crucial for the health of the nervous system. Abnormalities of the microtubule systems of axons and dendrites are a major contributor to neurodegenerative diseases. The purpose of this review is to provide a brief overview of contemporary knowledge of neuronal microtubules and how they may go awry during degeneration of the diseased nervous system.

\section{Microtubule organization in neurons}

Tubulin is a heterodimer of alpha tubulin and beta tubulin, each of which is a different primary gene product believed to have diverged evolutionarily from a single gene (1). In vertebrates, there are multiple alpha tubulin genes and multiple beta tubulin genes. In the test tube, microtubules can be nucleated de novo if there is a sufficient concentration of free tubulin, as well as the presence of GTP and appropriate temperature and buffer conditions. In living cells, de novo nucleation is suppressed so that nucleation of microtubules is favored to occur from nucleating structures that are usually components of "microtubule-organizing centers" such as the centrosome. The nucleating structures are 
called gamma-turcs (gamma tubulin ring complexes) because they consist of gamma tubulin, together with other proteins that combine with gamma-tubulin to form a template for the nucleation of new microtubules $(2,3)$. Gamma tubulin is a separate gene product from alpha or beta tubulin, and binds specifically to beta tubulin to establish the polarity orientation of the microtubule that elongates away from the nucleating structure. Some microtubules may remain attached to their nucleating structures, while others may be released from their nucleating structures and then recaptured by other proteins within the microtubule-organizing center. Still other microtubules may be released and then transported away from the nucleating structure by molecular motor proteins. Which of these options predominates depends on the cell type and stage of development, for example with developing neurons displaying a great deal of transport of microtubules away from the centrosome after their release (4).

Because tubulin is a heterodimer rather than a homodimer, the microtubule is intrinsically polar with beta tubulin at the plus end and alpha-tubulin at the minus end. The plus end of the microtubule is favored for dynamic exchange of tubulin subunits, while the minus end is less favored. The structural polarity of the microtubule exists along its entire length and is recognized by molecular motor proteins, which are enzymes that move along the lattice of the microtubule. Cytoplasmic dynein moves toward the minus end of the microtubule, while most kinesins move toward the plus end. Because different cargoes interact with different motors, the polarity orientation of microtubules in different regions of the neuron is a major determinant of where different cargoes are transported, thus allowing for subcellular localization of cytoplasmic constituents (5). Microtubules in the axon are nearly uniformly oriented, with their plus ends directed away from the soma, while microtubules in vertebrate dendrites are non-uniformly oriented, with roughly equal numbers of microtubules of each orientation (6-8). These distinct microtubule polarity patterns, shown in figure 1 , are one of the most essential and earliest developmental differences to arise between axons and dendrites, and are undoubtedly of key 
importance for many of the compositional and morphological differences that distinguish the two types of processes (8). Other factors that contribute to the delivery of different cargoes to different compartments of the neuron include targeting information within the motor proteins themselves, posttranslational modifications of the tubulin subunits that comprise the microtubules in different regions of the neuron, and the microtubule-associated proteins that adorn the microtubules (9).

As mentioned above, microtubules in developing neurons are nucleated at the centrosome and then released for transport into axons and dendrites (10-13). Molecular motor proteins transport the microtubules with either plus-end leading (into axons and dendrites) or with minus-end leading (into dendrites only). In this manner, the molecular motor proteins that transport microtubules into axons and dendrites establish the distinct polarity patterns of microtubules in each type of process (14-18). Available data suggest that cytoplasmic dynein is the chief motor protein for transporting plus-end-out (i.e., plus end directed away from the cell body) microtubules into both axons and dendrites, while kinesin-6 and kinesin-12 share the responsibility of transporting minus-end-out microtubules into dendrites but not axons. Recent studies have shown that a protein concentrated in the axon initial segment called tripartite motif-containing protein 46 (TRIM46) may function along the axon's length to preserve the uniform polarity orientation of the microtubules against corruption $(19,20)$. This function appears to relate to the microtubule-bundling properties of TRIM46. Other studies have shown that the centrosome may become quiescent as the neuron matures (21), such that new microtubules arise only via the severing of existing microtubules or potentially through local nucleation mechanisms.

The microtubule arrays of the neuron consist of individual microtubules that assume a variety of lengths and degrees of stability. Individual microtubules generally do not traverse the entire length of an axon or dendrite. Some microtubules are only a few micrometers in length (or even less), while other 
microtubules can achieve lengths that exceed a hundred micrometers (22-25). Longer microtubules act both as architectural struts that oppose the retraction of the axon or the dendrite as well as railways for organelle transport. The short microtubules are highly mobile and provide the form by which tubulin is actively transported within the axon and presumably dendrites. A short mobile microtubule may elongate into a long stationary microtubule, or it may entirely or partially depolymerize to yield subunits for other microtubules to elongate.

\section{Microtubule dynamics and stability in neurons}

Microtubule dynamics in cells are governed by a mechanism known as dynamic instability (26-29) that depends on tubulin being a GTPase. Free tubulin associates with hydrolysable GTP. Both alpha and beta tubulin associate with GTP, however the GTP bound to alpha tubulin rests in the region where alpha and beta tubulin interact. Therefore, tubulin heterodimers are only able to hydrolyze the GTP bound to beta-tubulin and this hydrolysis changes the conformation of tubulin dimer-dimer interaction (i.e., the conformation of the protofilaments that make up microtubules). GTP-bound tubulin dimers tend to orient the microtubule in a straight conformation, whereas GDP-tubulin bends the lattice and "spring loads" the microtubule with potential energy that favors catastrophe, which is an explosive bout of disassembly (30). The hydrolysis of GTP-beta-tubulin to GDP-beta-tubulin only happens after the free tubulin has assembled into the microtubule. Because GTP hydrolysis takes time and because dynamics occur principally at the plus end of the microtubule, the region of the microtubule toward the minus end is richer in GDP-tubulin than the region toward the plus end. If GTP hydrolysis catches up to the addition of new tubulin such that there is no longer a ring of GTP-tubulins at the plus end, the microtubule undergoes catastrophe. The microtubule can keep assembling as long as there is a GTPtubulin "cap" at its plus end. Individual microtubules in a population may undergo assembly while 
others may at the same time undergo disassembly, depending on whether or not the GTP cap is lost from any individual microtubule.

Microtubules in the population can be stabilized either by the capture of their plus ends, for example by complexes that form at the plus-end of microtubules to promote polymerization and recruit microtubules to the cell cortex (e.g. CLIP and CLASP, respectively), or by proteins that bind to the microtubule lattice (31-33). When a microtubule or a region of a microtubule is stabilized, it may still undergo dynamics, albeit slower. A small portion of the microtubule mass in developing axons is so stable that it appears to undergo no subunit exchange whatsoever, and is resistant to factors such as cold, calcium and microtubule-depolymerizing drugs that cause microtubules to disassemble. This hyper-stable (traditionally called "cold-stable" due to its capacity to resist depolymerization in response to cold in biochemical preparations) portion of the microtubule mass is stabilized by polyamination of the tubulin, and comprises a much larger fraction of the microtubule mass in adult neurons relative to developing neurons $(34,35)$. Polyamination is different from other known modifications of tubulin associated with microtubule stability, namely acetylation and detyrosination, as these other modifications do not confer stability but rather accumulate on microtubules that are long-lived (36-39). In neurons, available data indicate that different microtubule stability classes exist as domains on individual microtubules, rather than as separate populations of microtubules. As shown in figure 1, a typical microtubule in a developing neuron is, on average, about half stable and half labile, with the stable domain toward the minus end of the microtubule and the labile domain toward the plus end of the microtubule (40). Polyaminated tubulin is sparse in developing neurons, but represents a substantial portion of the total tubulin in adult neurons. It has been posited that the polyaminated regions of microtubules are interspersed as patches along the microtubule (presumably within the stable domain), but this has not been sufficiently explored. 
After decades of study, mystery still surrounds the factors and pathways that account for the stability properties of neuronal microtubules (9). Many different proteins have been credited with stabilizing microtubules, including traditional MAPs (microtubule-associated proteins) such as tau, MAP2 and MAP1b, as well as other proteins that bind to the microtubule lattice such as doublecortin (41-43). Most proteins that interact with microtubules can stabilize them in vitro or if overexpressed in cells, assuming the concentration is high enough. Tau and its related family members, MAP2 and MAP4, have repeated microtubule-binding domains that are thought to bind in a series along the microtubule lattice to hold it together and thereby prevent depolymerization (33). However, the on/off rate of these proteins with the microtubule in living cells is only milliseconds (44), which seems inconsistent with tau or its family members stabilizing microtubules in a traditional sense of strong stabilizing protein-protein interactions. Curiously, tau and MAP1b are more enriched on the labile domains of microtubules in the distal region of growing axons than on microtubules in the main shaft of the axon where stable and labile domains intermingle (45-47). This suggests that these proteins may be more important for regulating stability than conferring stability. MAP6 (also called stable tubule only peptide) is more enriched on the stable microtubule domains (48), and hence may be a better candidate for endowing stable domains with their stability properties. One possibility is that microtubule stability in neurons is the result of the combination of many different stabilizers, but another possibility is that many proteins that display microtubule-stabilizing properties in vitro or when overexpressed in cells may not be stabilizers of microtubules in the physiological context.

Certain proteins promote microtubule depolymerization. Examples are stathmin and its neuron-specific variant called SCG10, which shift microtubules toward disassembly by sequestering tubulin subunits and by promoting catastrophe, as well as certain "depolymerizing" kinesins (kinesin-8 and kinesin-13) that 
use the forces of ATP hydrolysis to remove tubulin subunits from the ends of microtubules $(49,50)$. Fidgetin, a novel microtubule severing protein, appears to target labile domains of microtubules, creating short microtubule fragments that quickly depolymerize into free tubulin (51). Proteins that depolymerize microtubules can promote reorganization of microtubule networks by liberating tubulin from one microtubule for incorporation into other microtubules elsewhere in the cell. Such transfer of tubulin subunits from one microtubule to another occurs via passive diffusion of free tubulin, but can be augmented by active transport mechanisms, given that tubulin can be incorporated into short polymers that are transportable by motor proteins over longer distances before yielding their subunits for the elongation of other microtubules.

\section{Microtubule end-targeting proteins}

+tips are proteins that associate with the plus end of the microtubule during bouts of assembly. Some have their own affinity for the plus end of the microtubule, by recognizing the GTP cap, while others have an affinity for other +tips and become +tips themselves for that reason. These proteins include EB1, EB3, CLIPs, CLASPs and others (52). Fluorescently conjugated +tips are useful for live-cell imaging of microtubule assembly and organization in cells. In neurons, +tips can influence the assembly dynamics of the microtubule, and integrate its behavior with a variety of proteins and structures (53). +tips are also important players in the "search and capture" mechanism of microtubule-stabilization, wherein a microtubule undergoing bouts of dynamic instability can be selectively stabilized by plus end capture by other cellular structures. This can be important, for example, in stabilizing microtubules on the side of a cell corresponding to the direction of migration, in response to an environmental cue. In this regard, +tips have important roles in growth cone behaviors (54). Recent studies suggest interesting relationships between +tips and more classic microtubule-associated proteins, for example with overexpression of EB1 rescuing the axogenesis impairment phenotype of MAP1B knockout (55). 
Recent studies have revealed a new category of proteins called calmodulin-regulated spectrinassociated proteins (CAMSAPs) (56). CAMSAPs, sometimes referred to as minus-end binding proteins, bind to free minus-ends of microtubules in various cells, and thereby block dynamics at that end of the microtubule (57). Vertebrate neurons express CAMSAP-1, CAMSAP-2, and CAMSAP-3, with CAMSAP2 being the predominant CAMSAP in these cells. Immunostained or ectopically-expressed fluorescentlytagged CAMSAPs appear as short stretches along the microtubule toward its minus end. This suggests that CAMSAPs compete with tubulin subunits for the minus end of the microtubule, until enough CAMSAP accumulates to limit any further dynamics. Depletion of CAMSAPs from neurons has detrimental effects on microtubule levels and stability and results in underdeveloped neuronal morphologies (58). Additional information on CAMSAP distribution in neurons will potentially reveal important insights into microtubule regulation in various neuronal compartments.

\section{Microtubule-severing proteins}

Microtubule-related proteins are AAA enzymes that form hexamers on the surface of the microtubule. The hexamers yank on a tubulin subunit to extract it from the microtubule lattice, causing the microtubule to break $(59,60)$. Such severing of microtubules can occur near their minus ends within the centrosome to release the microtubule so that it can then be transported into an axon or a dendrite. Severing can also occur at the plus end so that subunits are peeled off the more dynamic end of the microtubule. If the severing occurs in the stable domain, the result is two new microtubules, one with a stable and labile domain, and the other exclusively a stable fragment that can then assemble a new labile domain. In this manner, severing in the stable domain creates new microtubules. This is important for axonal and dendritic growth and branching to supply new microtubules for elongation and engorgement; thus reducing the dependence on new microtubules from the centrosome. Mobile 
microtubules observed in the axons of cultured neurons are generally about 7 micrometers in length and stable $(61,62)$, and hence presumably arise from the severing of longer microtubules in their stable domains. If the severing occurs in the labile domain, the result would be one microtubule with a stable domain and a shorter labile domain, as the microtubule fragment without a stable domain would presumably vanish as it would completely depolymerize (63). Thus, severing in the labile domain would not create new microtubules, but rather would pare down the labile domains, keeping them shorter than they would otherwise be. It is likely that the existence of multiple severing proteins allows for certain ones to target the stable domain and others to target the labile domain. Tight regulation of the expression levels and activities of the various severing proteins could thereby impose control over the expansion or tamping back of the microtubule array during axon growth, non-growth or retraction. This would be reminiscent of the circumstances in Drosophila cells undergoing mitosis, wherein katanin, spastin, and fidgetin play unique roles in the microtubule-mediated movement of chromosomes (64).

Katanin and spastin are microtubule-severing proteins with a preference for severing in the stable domain of the microtubule, resulting from a preference for tubulins that have been post-translationally acetylated or polyglutamylated $(65,66)$. Suppressing katanin or spastin can be deleterious to axonal growth and branching $(13,67-69)$, as would be expected, given the important roles these proteins play in generating new microtubules via the severing of existing ones. Recent data suggest that fidgetin targets labile domains of microtubules through a preference for tubulins that are not posttranslationally acetylated (51). Knocking down fidgetin causes axons of fetal cortical neurons to grow longer, potentially due to elongation of the labile domains of microtubules (51). Thus knocking down or inhibiting proteins that prune the labile domain, such as fidgetin, may be a useful therapeutic approach for elevating labile microtubule mass in injured or diseased axons. 


\section{The tubulin code}

Why do cells so tightly regulate tubulin post-translational modifications that do not impose stability on microtubules directly, but often reflect their stability? A great deal of evidence suggests that posttranslational modifications of tubulin impose a "code" on the microtubule that is read by other proteins $(37,70)$. The idea is that many microtubule-related proteins have preferential affinities for microtubules (or domains of a microtubule) that are enriched or deficient in certain modified tubulins. For example, kinesin-1 prefers microtubules rich in detyrosinated and acetylated tubulins, while kinesins 5 and 13 prefer microtubules rich in tyrosinated tubulin (71-73). Thus, the post-translational modifications of a microtubule may make it a more or less favored substrate for proteins such as molecular motors. Other examples of proteins sensitive to the tubulin code include microtubule-severing proteins, as discussed earlier $(51,65,66)$, and certain +tips that have a preference for tyrosinated over detyrosinated tubulin (74). This is important because when experiments demonstrate a functional role for stable or labile microtubules (or domains of a microtubule), it may not be the stability properties of the microtubule, per se, that is relevant so much as the tubulin modifications that accompany the microtubule's stability properties.

The tubulin code is regulated by highly conserved and tightly regulated enzymes, and for some modifications, the enzymes orchestrate a cycle wherein the modification is imposed only after assembly of the tubulin into the microtubule and only reversed when the tubulin subunits are liberated from the microtubule during bouts of disassembly. For example, the enzymes may be differentially enriched or regulated in axons versus dendrites, enabling axonal microtubules to be richer in post-translationally modified tubulin subunits compared to dendritic microtubules. These enzymes provide a hub for regulation of the tubulin code, and may also provide an avenue for therapeutics, as they can be 
experimentally or clinically manipulated to change the tubulin code in a manner that might be conducive to reversing the ill effects of disease.

A recent article on nerve regeneration after injury provides a good example of the potential for therapeutics, based on manipulating the tubulin code. Transgenic mice with constitutively active GSK3 displayed decreased detyrosination of microtubules in growth cones of injured axons as well as improved sciatic nerve regeneration (75). Drugs that inhibit tubulin detyrosination resulted in similar regenerative enhancing effects, whereas microtubule stabilization negated these effects. These findings support the notion that manipulating the tubulin code has different effects than simply manipulating microtubule stability, thus providing different tools to achieve changes in the microtubule array that may assist in treating various disease or injury scenarios.

\section{Microtubule defects in nervous system disease}

The various aspects of the neuronal microtubule arrays thus far discussed can be corrupted over the life of the neuron by the aging process as well as by neurodegenerative disease mechanisms. For example, the axon must preserve a nearly uniform polarity orientation of microtubules in order for the anterograde and retrograde transport of various cargoes to be properly orchestrated. Corruption of the microtubule polarity pattern (i.e., appearance of too many mal-oriented microtubules) would send cargoes moving in the wrong direction and potentially cause traffic jams. Preserving the microtubule polarity pattern of the axon is ongoing work for the neuron, requiring cytoplasmic dynein to transport mal-oriented microtubules back to the cell body (76). This clearing mechanism could be overwhelmed by pathogenic factors that promote the formation of mal-oriented microtubules or the flipping of short microtubules. The clearing mechanism itself could also be degraded by pathology. This has not yet been 
explored in the context of known diseases, but mutation of the fly ortholog of an epilepsy gene causes notable microtubule polarity flaws in the axon (77).

Microtubule loss (i.e. reduction in microtubule mass) from axons and dendrites is often associated with neurodegenerative diseases $(78,79)$. This is best documented in diseases called tauopathies, in which tau dissociates from microtubules as a result of abnormal phosphorylation $(80,81)$. Pure tauopathies result from mutations that render tau prone to such effects. Tau is not mutated in Alzheimer's disease, but rather becomes hyper-phosphorylated in response to abnormal amyloid- $\beta$ (82). Popularly, microtubules are said to disintegrate as they lose tau, due to the microtubules being destabilized (27). Such a mechanism would suggest that stable domains of microtubules become labile, which would then somehow lead to a degradation of the microtubule mass. Another theory posits that detachment of tau from microtubules causes them to become more sensitive to microtubule-severing proteins, mainly katanin $(83,84)$. There has also been evidence that tau tangles themselves can promote microtubule depolymerization (85), and the same could be true of soluble abnormal tau. For example, abnormal tau, either in the form of soluble protein or in the form of abnormal filaments, is known to produce toxicity that could theoretically contribute to microtubule loss via Tau's phosphatase-activating domain (86). When tau abnormally enters dendrites during Alzheimer's disease, recent evidence suggests that dendritic microtubules degrade because they become more polyglutamylated and hence more sensitive to spastin (87). Loss-of-function and gain-of-function mechanisms may apply to various neurodegenerative disorders in which loss of microtubule mass or a change in microtubule dynamics or stability has been observed, including Amyotrophic Lateral Sclerosis, Hereditary Spastic Paraplegia, Parkinson's disease, and others (88-91). Figure 2 shows potential mechanisms of microtubule loss during axonal degeneration, as well as a potential contribution to axonal degeneration of microtubule polarity flaws, as discussed earlier. 
Some investigators have posited that neurons afflicted with tauopathies and other neurodegenerative diseases may benefit by treatment with microtubule-stabilizing drugs. Animal models for neurodegenerative diseases and injuries have shown histological and behavioral improvements when treated with microtubule-stabilizing drugs (92-96). In human patients, there are potential problems of increasing microtubule stability throughout the neuron and throughout the entire nervous system, especially if the drugs are taken systematically (97). It has been posited that a better idea than microtubule-stabilizing drugs may be the development of drugs that inhibit microtubule-severing proteins so that deficits in the stable or labile domains can be specifically corrected (63). A shift in focus of the research community from stabilizing existing microtubules to adding labile microtubule mass (via the elongation of labile domains of microtubules) to the degenerating axon or dendrite may benefit a number of different disease and injury scenarios. Therapies that target severing proteins are certainly not the only avenue by which this could be accomplished, as inhibition of other proteins that limit microtubule assembly, such as stathmin (98), could also be helpful. +tips are another potentially powerful target for affecting microtubule dynamics; for example, overexpression of TACC3, a +tip in frog, increases axon length, presumably by enabling the elongation of labile domains of microtubules (65).

The past decade has seen a plethora of work on other mechanisms (besides microtubule loss) by which cytoskeletal mechanisms might go awry during neurodegenerative diseases. For example, in Huntington's disease, there are findings suggesting that mutant huntingtin protein abnormally folds on the microtubule lattice to cover more surface area than it normally would and thereby impedes organelle transport by physically blocking the microtubule's interaction with motor proteins (99). Relevant to Alzheimer's disease, beta amyloid has been shown to impair hippocampal long-term 
potentiation and promote dendritic spine loss through a pathway involving kinesin-5 (100), a motor protein that may contribute to the regulation of microtubule polarity orientation in dendrites (72). Audouard et al. (101) recently showed that disrupted axonal transport precedes progressive muscle denervation in mice expressing pathogenic human tau, while Stevenson et al. (102) used squid giant axon to show that amyloid precursor protein interacts at the organelle/microtubule interface, possibly mediating vesicular transport and Alzheimer's pathology. Gan et al. (103) proposed that the disruption of axonal transport by a mutant kinesin light chain-1 splice variant in Alzheimer's disease follows a progression of reduced axonal transport, which leads to accumulation of protein aggregates, followed by an ER stress response. These examples illustrate that the literature is growing at a rapid pace, with novel mechanistic hypotheses pushing the field toward a better understanding of etiology and potential therapeutics.

The ill effects on microtubules of any particular neurodegenerative disease may be a primary factor in axonal and/or dendritic degeneration or may contribute secondarily. Regardless, development of therapeutics capable of correcting these microtubule abnormalities will undoubtedly improve the status of the degenerating nervous system. Future drug development will likely be directed toward inhibitors of specific proteins or pathways that affect microtubules, in order to shift the status of the diseased microtubule array back toward normal. 


\section{Figure Legends}

Figure 1. Microtubules are oriented differently in the axon and the dendrites. Microtubules in axons are nearly uniformly oriented with plus ends distal to the cell body while microtubules in dendrites are non-uniformly oriented. Microtubules consist of a labile domain (yellow) toward the plus end of the microtubule and a stable domain (red) toward the minus end of the microtubule.

\section{Figure 2. Corruption of the axonal microtubule array contributing to axonal degeneration during}

disease. Panel $\mathbf{A}$ shows the healthy adult neuron in which axonal microtubules are oriented with their plus ends (and labile domains, yellow) away from the cell body, and their minus ends (and stable domains, red) toward the cell body. Three potential mechanisms for microtubule loss during degeneration are shown in panels B-D). B) Microtubule destabilization is the conversion of a previously stable domain into a labile one. This leads to large portions of a microtubule susceptible to catastrophic events and thus results in microtubule disassembly. C) The labile domain of a microtubule is preferentially depolymerized, leaving behind mainly stable domains of microtubules. D) Microtubules become more sensitive to breakage by microtubule-severing proteins, with the breakage leading to microtubule depolymerization. Depending on the particular severing protein, this could preferentially affect either the labile or the stable domains. Panel E shows the healthy adult neuron with microtubules providing railways for motor-based organelle transport. Panel $\mathbf{F}$ represents traffic jams and other abnormalities in organelle transport resulting from microtubule polarity flaws in the axon (i.e., microtubules of inverse orientation). This can lead to axonal swelling and ultimately degeneration. Variations on these various pathogenic scenarios can also occur in dendrites (not shown). 


\section{Acknowledgments}

The work of the authors is currently supported by grants to PWB from the Craig H. Neilsen Foundation (Grant 259350), the National Institutes of Health (NIH; NINDS; Grant R01 NS28785), the Department of Defense (GW120037 and GW140086), and the State of Pennsylvania Tobacco Settlement Funds. 


\section{References}

1. Keeling PJ, Doolittle WF. Alpha-tubulin from early-diverging eukaryotic lineages and the evolution of the tubulin family. Mol Biol Evol. 1996;13(10):1297-305. PubMed PMID: 8952074.

2. Zheng $\mathrm{Y}$, Wong ML, Alberts B, Mitchison T. Nucleation of microtubule assembly by a gammatubulin-containing ring complex. Nature. 1995;378(6557):578-83. doi: 10.1038/378578a0. PubMed PMID: 8524390.

3. Oakley BR, Paolillo V, Zheng Y. gamma-Tubulin complexes in microtubule nucleation and beyond. Mol Biol Cell. 2015;26(17):2957-62. doi: 10.1091/mbc.E14-11-1514. PubMed PMID: 26316498; PMCID: PMC4551311.

4. Baas PW, Karabay A, Qiang L. Microtubules cut and run. Trends in cell biology. 2005;15(10):51824. Epub 2005/08/30. doi: 10.1016/j.tcb.2005.08.004. PubMed PMID: 16126385.

5. Cole NB, Lippincott-Schwartz J. Organization of organelles and membrane traffic by microtubules. Current opinion in cell biology. 1995;7(1):55-64. PubMed PMID: 7755990.

6. Baas PW, Deitch JS, Black MM, Banker GA. Polarity orientation of microtubules in hippocampal neurons: uniformity in the axon and nonuniformity in the dendrite. Proceedings of the National Academy of Sciences of the United States of America. 1988;85(21):8335-9. PubMed PMID: 3054884; PMCID: 282424.

7. Baas PW, Black MM, Banker GA. Changes in microtubule polarity orientation during the development of hippocampal neurons in culture. The Journal of cell biology. 1989;109(6 Pt 1):3085-94. PubMed PMID: 2592416; PMCID: 2115969.

8. Baas PW, Lin S. Hooks and comets: The story of microtubule polarity orientation in the neuron. Developmental neurobiology. 2011;71(6):403-18. doi: 10.1002/dneu.20818. PubMed PMID: 21557497; PMCID: 3151545.

9. Baas PW, Rao AN, Matamoros AJ, Leo L. Stability properties of neuronal microtubules. Cytoskeleton (Hoboken). 2016. doi: 10.1002/cm.21286. PubMed PMID: 26887570.

10. Yu W, Centonze VE, Ahmad FJ, Baas PW. Microtubule nucleation and release from the neuronal centrosome. The Journal of cell biology. 1993;122(2):349-59. PubMed PMID: 8320258; PMCID: 2119640.

11. Ahmad FJ, Joshi HC, Centonze VE, Baas PW. Inhibition of microtubule nucleation at the neuronal centrosome compromises axon growth. Neuron. 1994;12(2):271-80. PubMed PMID: 8110458.

12. Ahmad FJ, Baas PW. Microtubules released from the neuronal centrosome are transported into the axon. Journal of cell science. 1995;108 ( Pt 8):2761-9. PubMed PMID: 7593317.

13. Ahmad FJ, Yu W, McNally FJ, Baas PW. An essential role for katanin in severing microtubules in the neuron. The Journal of cell biology. 1999;145(2):305-15. PubMed PMID: 10209026; PMCID:

2133110.

14. Baas PW, Ahmad FJ. The transport properties of axonal microtubules establish their polarity orientation. The Journal of cell biology. 1993;120(6):1427-37. PubMed PMID: 8449987; PMCID: 2119746.

15. Yu W, Sharp DJ, Kuriyama R, Mallik P, Baas PW. Inhibition of a mitotic motor compromises the formation of dendrite-like processes from neuroblastoma cells. The Journal of cell biology. 1997;136(3):659-68. PubMed PMID: 9024695; PMCID: 2134303.

16. Sharp DJ, Kuriyama R, Essner R, Baas PW. Expression of a minus-end-directed motor protein induces Sf9 cells to form axon-like processes with uniform microtubule polarity orientation. Journal of cell science. 1997;110 ( Pt 19):2373-80. PubMed PMID: 9410876.

17. Ahmad FJ, Echeverri CJ, Vallee RB, Baas PW. Cytoplasmic dynein and dynactin are required for the transport of microtubules into the axon. The Journal of cell biology. 1998;140(2):391-401. PubMed PMID: 9442114; PMCID: 2132571. 
18. Lin S, Liu M, Mozgova OI, Yu W, Baas PW. Mitotic motors coregulate microtubule patterns in axons and dendrites. The Journal of neuroscience : the official journal of the Society for Neuroscience. 2012;32(40):14033-49. doi: 10.1523/JNEUROSCI.3070-12.2012. PubMed PMID: 23035110; PMCID: PMC3482493.

19. Curcio M, Bradke F. Microtubule Organization in the Axon: TRIM46 Determines the Orientation. Neuron. 2015;88(6):1072-5. doi: 10.1016/j.neuron.2015.12.006. PubMed PMID: 26687215.

20. van Beuningen SF, Will L, Harterink M, Chazeau A, van Battum EY, Frias CP, Franker MA, Katrukha EA, Stucchi R, Vocking K, Antunes AT, Slenders L, Doulkeridou S, Sillevis Smitt P, Altelaar AF, Post JA, Akhmanova A, Pasterkamp RJ, Kapitein LC, de Graaff E, Hoogenraad CC. TRIM46 Controls Neuronal Polarity and Axon Specification by Driving the Formation of Parallel Microtubule Arrays. Neuron. 2015;88(6):1208-26. doi: 10.1016/j.neuron.2015.11.012. PubMed PMID: 26671463.

21. Baas PW, Falnikar A. Re-evaluation of the Neuronal Centrosome as a Generator of Microtubules for Axons and Dendrites. In: Schatten H, editor. The Centrosome: Cell and Molecular Mechanisms of Functions and Dysfunctions in Disease. Totowa, NJ: Humana Press; 2012. p. 309-26.

22. Bray $D$, Bunge MB. Serial analysis of microtubules in cultured rat sensory axons. Journal of neurocytology. 1981;10(4):589-605. PubMed PMID: 7310467.

23. Tsukita S, Usukura J, Tsukita S, Ishikawa H. The cytoskeleton in myelinated axons: a freeze-etch replica study. Neuroscience. 1982;7(9):2135-47. PubMed PMID: 6890638.

24. Letourneau PC. Analysis of microtubule number and length in cytoskeletons of cultured chick sensory neurons. The Journal of neuroscience : the official journal of the Society for Neuroscience. 1982;2(6):806-14. PubMed PMID: 7086485.

25. Yu W, Baas PW. Changes in microtubule number and length during axon differentiation. The Journal of neuroscience : the official journal of the Society for Neuroscience. 1994;14(5 Pt 1):2818-29. PubMed PMID: 8182441.

26. Mitchison T, Kirschner M. Dynamic instability of microtubule growth. Nature. 1984;312(5991):237-42. PubMed PMID: 6504138.

27. Drechsel DN, Hyman AA, Cobb MH, Kirschner MW. Modulation of the dynamic instability of tubulin assembly by the microtubule-associated protein tau. Mol Biol Cell. 1992;3(10):1141-54. PubMed PMID: 1421571; PMCID: PMC275678.

28. Waterman-Storer CM, Salmon ED. Actomyosin-based retrograde flow of microtubules in the lamella of migrating epithelial cells influences microtubule dynamic instability and turnover and is associated with microtubule breakage and treadmilling. The Journal of cell biology. 1997;139(2):417-34. PubMed PMID: 9334345; PMCID: PMC2139796.

29. Burbank KS, Mitchison TJ. Microtubule dynamic instability. Current biology : CB. 2006;16(14):R516-7. doi: 10.1016/j.cub.2006.06.044. PubMed PMID: 16860721.

30. Bailey ME, Jiang N, Dima RI, Ross JL. Microtubule severing enzymes couple ATPase activity with tubulin GTPase spring loading. Biopolymers. 2016. doi: 10.1002/bip.22842. PubMed PMID: 27037673.

31. Folker ES, Baker BM, Goodson HV. Interactions between CLIP-170, tubulin, and microtubules: implications for the mechanism of Clip-170 plus-end tracking behavior. Mol Biol Cell. 2005;16(11):537384. doi: 10.1091/mbc.E04-12-1106. PubMed PMID: 16120651; PMCID: PMC1266433.

32. Lansbergen G, Grigoriev I, Mimori-Kiyosue Y, Ohtsuka T, Higa S, Kitajima I, Demmers J, Galjart N, Houtsmuller AB, Grosveld F, Akhmanova A. CLASPs attach microtubule plus ends to the cell cortex through a complex with LL5beta. Dev Cell. 2006;11(1):21-32. doi: 10.1016/j.devcel.2006.05.012. PubMed PMID: 16824950.

33. Kadavath H, Hofele RV, Biernat J, Kumar S, Tepper K, Urlaub H, Mandelkow E, Zweckstetter M. Tau stabilizes microtubules by binding at the interface between tubulin heterodimers. Proceedings of the National Academy of Sciences of the United States of America. 2015;112(24):7501-6. doi: 10.1073/pnas.1504081112. PubMed PMID: 26034266; PMCID: PMC4475932. 
34. Brady ST, Tytell M, Lasek RJ. Axonal tubulin and axonal microtubules: biochemical evidence for cold stability. The Journal of cell biology. 1984;99(5):1716-24. PubMed PMID: 6490717; PMCID: 2113352.

35. Baas PW. Microtubule stability in the axon: new answers to an old mystery. Neuron. 2013;78(1):3-5. doi: 10.1016/j.neuron.2013.03.012. PubMed PMID: 23583103.

36. Song Y, Brady ST. Post-translational modifications of tubulin: pathways to functional diversity of microtubules. Trends Cell Biol. 2015;25(3):125-36. doi: 10.1016/j.tcb.2014.10.004. PubMed PMID: 25468068; PMCID: PMC4344850.

37. Garnham CP, Roll-Mecak A. The chemical complexity of cellular microtubules: tubulin posttranslational modification enzymes and their roles in tuning microtubule functions. Cytoskeleton. 2012;69(7):442-63. doi: 10.1002/cm.21027. PubMed PMID: 22422711; PMCID: PMC3459347.

38. Lim SS, Sammak PJ, Borisy GG. Progressive and spatially differentiated stability of microtubules in developing neuronal cells. The Journal of cell biology. 1989;109(1):253-63. PubMed PMID: 2745551; PMCID: PMC2115470.

39. Howes SC, Alushin GM, Shida T, Nachury MV, Nogales E. Effects of tubulin acetylation and tubulin acetyltransferase binding on microtubule structure. Mol Biol Cell. 2014;25(2):257-66. doi: 10.1091/mbc.E13-07-0387. PubMed PMID: 24227885; PMCID: PMC3890346.

40. Baas PW, Black MM. Individual microtubules in the axon consist of domains that differ in both composition and stability. The Journal of cell biology. 1990;111(2):495-509. PubMed PMID: 2199458; PMCID: 2116207.

41. Tucker RP. The roles of microtubule-associated proteins in brain morphogenesis: a review. Brain research Brain research reviews. 1990;15(2):101-20. PubMed PMID: 2282447.

42. Mandelkow E, Mandelkow EM. Microtubules and microtubule-associated proteins. Current opinion in cell biology. 1995;7(1):72-81. Epub 1995/02/01. PubMed PMID: 7755992.

43. Dehmelt L, Halpain S. The MAP2/Tau family of microtubule-associated proteins. Genome biology. 2005;6(1):204. doi: 10.1186/gb-2004-6-1-204. PubMed PMID: 15642108; PMCID: 549057.

44. Janning D, Igaev M, Sundermann F, Bruhmann J, Beutel O, Heinisch JJ, Bakota L, Piehler J, Junge $\mathrm{W}$, Brandt R. Single-molecule tracking of tau reveals fast kiss-and-hop interaction with microtubules in living neurons. Molecular biology of the cell. 2014;25(22):3541-51. doi: 10.1091/mbc.E14-06-1099. PubMed PMID: 25165145; PMCID: 4230615.

45. Black MM, Slaughter T, Fischer I. Microtubule-associated protein 1b (MAP1b) is concentrated in the distal region of growing axons. The Journal of neuroscience : the official journal of the Society for Neuroscience. 1994;14(2):857-70. PubMed PMID: 8301365.

46. Black MM, Slaughter T, Moshiach S, Obrocka M, Fischer I. Tau is enriched on dynamic microtubules in the distal region of growing axons. The Journal of neuroscience : the official journal of the Society for Neuroscience. 1996;16(11):3601-19. PubMed PMID: 8642405.

47. Kempf M, Clement A, Faissner A, Lee G, Brandt R. Tau binds to the distal axon early in development of polarity in a microtubule- and microfilament-dependent manner. The Journal of neuroscience : the official journal of the Society for Neuroscience. 1996;16(18):5583-92. PubMed PMID: 8795614.

48. Slaughter T, Black MM. STOP (stable-tubule-only-polypeptide) is preferentially associated with the stable domain of axonal microtubules. Journal of neurocytology. 2003;32(4):399-413. doi: 10.1023/B:NEUR.0000011334.70648.87. PubMed PMID: 14724383.

49. Chauvin S, Sobel A. Neuronal stathmins: a family of phosphoproteins cooperating for neuronal development, plasticity and regeneration. Progress in neurobiology. 2015;126:1-18. doi: 10.1016/j.pneurobio.2014.09.002. PubMed PMID: 25449700. 
50. Niwa S. Kinesin superfamily proteins and the regulation of microtubule dynamics in morphogenesis. Anatomical science international. 2015;90(1):1-6. doi: 10.1007/s12565-014-0259-5. PubMed PMID: 25347970.

51. Leo L, Yu W, D'Rozario M, Waddell EA, Marenda DR, Baird MA, Davidson MW, Zhou B, Wu B, Baker L, Sharp DJ, Baas PW. Vertebrate Fidgetin Restrains Axonal Growth by Severing Labile Domains of Microtubules. Cell reports. 2015;12(11):1723-30. doi: 10.1016/j.celrep.2015.08.017. PubMed PMID: 26344772.

52. Akhmanova A, Hoogenraad CC. Microtubule plus-end-tracking proteins: mechanisms and functions. Current opinion in cell biology. 2005;17(1):47-54. doi: 10.1016/j.ceb.2004.11.001. PubMed PMID: 15661518.

53. Bearce EA, Erdogan B, Lowery LA. TIPsy tour guides: how microtubule plus-end tracking proteins (+TIPs) facilitate axon guidance. Front Cell Neurosci. 2015;9:241. doi: 10.3389/fncel.2015.00241. PubMed PMID: 26175669; PMCID: PMC4485311.

54. Neukirchen D, Bradke F. Neuronal polarization and the cytoskeleton. Semin Cell Dev Biol. 2011;22(8):825-33. doi: 10.1016/j.semcdb.2011.08.007. PubMed PMID: 21884814.

55. Jimenez-Mateos EM, Paglini G, Gonzalez-Billault C, Caceres A, Avila J. End binding protein-1 (EB1) complements microtubule-associated protein-1B during axonogenesis. Journal of neuroscience research. 2005;80(3):350-9. doi: 10.1002/jnr.20453. PubMed PMID: 15789376.

56. Akhmanova A, Hoogenraad CC. Microtubule minus-end-targeting proteins. Current biology : CB. 2015;25(4):R162-71. doi: 10.1016/j.cub.2014.12.027. PubMed PMID: 25689915.

57. Jiang K, Hua S, Mohan R, Grigoriev I, Yau KW, Liu Q, Katrukha EA, Altelaar AF, Heck AJ, Hoogenraad CC, Akhmanova A. Microtubule minus-end stabilization by polymerization-driven CAMSAP deposition. Developmental cell. 2014;28(3):295-309. doi: 10.1016/j.devcel.2014.01.001. PubMed PMID: 24486153.

58. Yau KW, van Beuningen SF, Cunha-Ferreira I, Cloin BM, van Battum EY, Will L, Schatzle P, Tas RP, van Krugten J, Katrukha EA, Jiang K, Wulf PS, Mikhaylova M, Harterink M, Pasterkamp RJ, Akhmanova A, Kapitein LC, Hoogenraad CC. Microtubule minus-end binding protein CAMSAP2 controls axon specification and dendrite development. Neuron. 2014;82(5):1058-73. doi: 10.1016/j.neuron.2014.04.019. PubMed PMID: 24908486.

59. Roll-Mecak A, Vale RD. Making more microtubules by severing: a common theme of noncentrosomal microtubule arrays? The Journal of cell biology. 2006;175(6):849-51. doi: 10.1083/jcb.200611149. PubMed PMID: 17178905; PMCID: 2064694.

60. Roll-Mecak A, McNally FJ. Microtubule-severing enzymes. Current opinion in cell biology. 2010;22(1):96-103. doi: 10.1016/j.ceb.2009.11.001. PubMed PMID: 19963362; PMCID: 2822099.

61. Wang L, Brown A. Rapid movement of microtubules in axons. Current biology : CB. 2002;12(17):1496-501. PubMed PMID: 12225664.

62. He Y, Francis F, Myers KA, Yu W, Black MM, Baas PW. Role of cytoplasmic dynein in the axonal transport of microtubules and neurofilaments. The Journal of cell biology. 2005;168(5):697-703. doi: 10.1083/jcb.200407191. PubMed PMID: 15728192; PMCID: PMC2171826.

63. Jean DC, Baas PW. It cuts two ways: microtubule loss during Alzheimer disease. The EMBO journal. 2013;32(22):2900-2. doi: 10.1038/emboj.2013.219. PubMed PMID: 24076651; PMCID: 3831311. 64. Zhang D, Rogers GC, Buster DW, Sharp DJ. Three microtubule severing enzymes contribute to the "Pacman-flux" machinery that moves chromosomes. The Journal of cell biology. 2007;177(2):231-42. doi: $10.1083 / j c b .200612011$.

65. Lacroix B, van Dijk J, Gold ND, Guizetti J, Aldrian-Herrada G, Rogowski K, Gerlich DW, Janke C. Tubulin polyglutamylation stimulates spastin-mediated microtubule severing. The Journal of cell biology. 2010;189(6):945-54. doi: 10.1083/jcb.201001024. PubMed PMID: 20530212; PMCID: 2886356. 
66. Sudo H, Baas PW. Acetylation of microtubules influences their sensitivity to severing by katanin in neurons and fibroblasts. The Journal of neuroscience : the official journal of the Society for Neuroscience. 2010;30(21):7215-26. Epub 2010/05/28. doi: 10.1523/jneurosci.0048-10.2010. PubMed PMID: 20505088; PMCID: Pmc2891103.

67. Karabay A, Yu W, Solowska JM, Baird DH, Baas PW. Axonal growth is sensitive to the levels of katanin, a protein that severs microtubules. The Journal of neuroscience : the official journal of the Society for Neuroscience. 2004;24(25):5778-88. doi: 10.1523/JNEUROSCI.1382-04.2004. PubMed PMID: 15215300 .

68. Yu W, Qiang L, Solowska JM, Karabay A, Korulu S, Baas PW. The microtubule-severing proteins spastin and katanin participate differently in the formation of axonal branches. Molecular biology of the cell. 2008;19(4):1485-98. doi: 10.1091/mbc.E07-09-0878. PubMed PMID: 18234839; PMCID: 2291400.

69. Qiang L, Yu W, Liu M, Solowska JM, Baas PW. Basic fibroblast growth factor elicits formation of interstitial axonal branches via enhanced severing of microtubules. Molecular biology of the cell. 2010;21(2):334-44. doi: 10.1091/mbc.E09-09-0834. PubMed PMID: 19940015; PMCID: 2808232.

70. Yu I, Garnham CP, Roll-Mecak A. Writing and Reading the Tubulin Code. The Journal of biological chemistry. 2015;290(28):17163-72. doi: 10.1074/jbc.R115.637447. PubMed PMID: 25957412; PMCID: PMC4498056.

71. Peris L, Wagenbach M, Lafanechere L, Brocard J, Moore AT, Kozielski F, Job D, Wordeman L, Andrieux A. Motor-dependent microtubule disassembly driven by tubulin tyrosination. The Journal of cell biology. 2009;185(7):1159-66. doi: 10.1083/jcb.200902142. PubMed PMID: 19564401; PMCID: 2712961.

72. Kahn OI, Sharma V, Gonzalez-Billault C, Baas PW. Effects of kinesin-5 inhibition on dendritic architecture and microtubule organization. Mol Biol Cell. 2015;26(1):66-77. doi: 10.1091/mbc.E14-081313. PubMed PMID: 25355946; PMCID: PMC4279230.

73. Sirajuddin M, Rice LM, Vale RD. Regulation of microtubule motors by tubulin isotypes and posttranslational modifications. Nat Cell Biol. 2014;16(4):335-44. doi: 10.1038/ncb2920. PubMed PMID: 24633327; PMCID: PMC4117587.

74. Peris L, Thery M, Faure J, Saoudi Y, Lafanechere L, Chilton JK, Gordon-Weeks P, Galjart N, Bornens M, Wordeman L, Wehland J, Andrieux A, Job D. Tubulin tyrosination is a major factor affecting the recruitment of CAP-Gly proteins at microtubule plus ends. The Journal of cell biology. 2006;174(6):839-49. doi: 10.1083/jcb.200512058. PubMed PMID: 16954346; PMCID: 2064338.

75. Gobrecht P, Andreadaki A, Diekmann H, Heskamp A, Leibinger M, Fischer D. Promotion of Functional Nerve Regeneration by Inhibition of Microtubule Detyrosination. The Journal of neuroscience : the official journal of the Society for Neuroscience. 2016;36(14):3890-902. doi: 10.1523/JNEUROSCI.4486-15.2016. PubMed PMID: 27053198.

76. Baas PW, Mozgova Ol. A novel role for retrograde transport of microtubules in the axon. Cytoskeleton (Hoboken). 2012;69(7):416-25. doi: 10.1002/cm.21013. PubMed PMID: 22328357. 77. Ehaideb SN, lyengar A, Ueda A, lacobucci GJ, Cranston C, Bassuk AG, Gubb D, Axelrod JD, Gunawardena S, Wu CF, Manak JR. prickle modulates microtubule polarity and axonal transport to ameliorate seizures in flies. Proceedings of the National Academy of Sciences of the United States of America. 2014;111(30):11187-92. doi: 10.1073/pnas.1403357111. PubMed PMID: 25024231; PMCID: PMC4121842.

78. Zempel $\mathrm{H}$, Mandelkow EM. Linking amyloid-beta and tau: amyloid-beta induced synaptic dysfunction via local wreckage of the neuronal cytoskeleton. Neurodegener Dis. 2012;10(1-4):64-72. doi: 10.1159/000332816. PubMed PMID: 22156588.

79. Dubey J, Ratnakaran N, Koushika SP. Corrigendum: Neurodegeneration and microtubule dynamics: death by a thousand cuts. Front Cell Neurosci. 2016;10:26. doi: 10.3389/fncel.2016.00026. PubMed PMID: 26903811; PMCID: PMC4746346. 
80. Duan Y, Dong S, Gu F, Hu Y, Zhao Z. Advances in the pathogenesis of Alzheimer's disease: focusing on tau-mediated neurodegeneration. Translational neurodegeneration. 2012;1(1):24. doi: 10.1186/2047-9158-1-24. PubMed PMID: 23241453; PMCID: 3598890.

81. Yoshiyama Y, Lee VM, Trojanowski JQ. Therapeutic strategies for tau mediated neurodegeneration. Journal of neurology, neurosurgery, and psychiatry. 2013;84(7):784-95. doi: 10.1136/jnnp-2012-303144. PubMed PMID: 23085937; PMCID: 3912572.

82. Sierra M, Gelpi E, Marti MJ, Compta Y. Lewy- and alzheimer-type pathologies in midbrain and cerebellum across the Lewy body disorders spectrum. Neuropathol Appl Neurobiol. 2016. doi: 10.1111/nan.12308. PubMed PMID: 26810462.

83. Qiang L, Yu W, Andreadis A, Luo M, Baas PW. Tau protects microtubules in the axon from severing by katanin. The Journal of neuroscience : the official journal of the Society for Neuroscience. 2006;26(12):3120-9. doi: 10.1523/JNEUROSCI.5392-05.2006. PubMed PMID: 16554463.

84. Sudo H, Baas PW. Strategies for diminishing katanin-based loss of microtubules in tauopathic neurodegenerative diseases. Human molecular genetics. 2011;20(4):763-78. doi: 10.1093/hmg/ddq521. PubMed PMID: 21118899; PMCID: 3024046.

85. Alonso AC, Grundke-lqbal I, Iqbal K. Alzheimer's disease hyperphosphorylated tau sequesters normal tau into tangles of filaments and disassembles microtubules. Nat Med. 1996;2(7):783-7. PubMed PMID: 8673924.

86. Kanaan NM, Morfini G, Pigino G, LaPointe NE, Andreadis A, Song Y, Leitman E, Binder LI, Brady ST. Phosphorylation in the amino terminus of tau prevents inhibition of anterograde axonal transport. Neurobiology of aging. 2012;33(4):826 e15-30. doi: 10.1016/j.neurobiolaging.2011.06.006. PubMed PMID: 21794954; PMCID: 3272324.

87. Zempel H, Luedtke J, Kumar Y, Biernat J, Dawson H, Mandelkow E, Mandelkow EM. Amyloidbeta oligomers induce synaptic damage via Tau-dependent microtubule severing by TTLL6 and spastin. The EMBO journal. 2013;32(22):2920-37. doi: 10.1038/emboj.2013.207. PubMed PMID: 24065130; PMCID: PMC3831312.

88. Fanara P, Banerjee J, Hueck RV, Harper MR, Awada M, Turner H, Husted KH, Brandt R, Hellerstein MK. Stabilization of hyperdynamic microtubules is neuroprotective in amyotrophic lateral sclerosis. The Journal of biological chemistry. 2007;282(32):23465-72. doi: 10.1074/jbc.M703434200. PubMed PMID: 17567579.

89. Solowska JM, D'Rozario M, Jean DC, Davidson MW, Marenda DR, Baas PW. Pathogenic mutation of spastin has gain-of-function effects on microtubule dynamics. The Journal of neuroscience : the official journal of the Society for Neuroscience. 2014;34(5):1856-67. doi: 10.1523/JNEUROSCI.330913.2014. PubMed PMID: 24478365; PMCID: PMC3905148.

90. Coyne AN, Siddegowda BB, Estes PS, Johannesmeyer J, Kovalik T, Daniel SG, Pearson A, Bowser $\mathrm{R}$, Zarnescu DC. Futsch/MAP1B mRNA is a translational target of TDP-43 and is neuroprotective in a Drosophila model of amyotrophic lateral sclerosis. The Journal of neuroscience : the official journal of the Society for Neuroscience. 2014;34(48):15962-74. doi: 10.1523/JNEUROSCI.2526-14.2014. PubMed PMID: 25429138; PMCID: 4244467.

91. Cappelletti G, Casagrande F, Calogero A, De Gregorio C, Pezzoli G, Cartelli D. Linking microtubules to Parkinson's disease: the case of parkin. Biochemical Society transactions. 2015;43(2):292-6. doi: 10.1042/BST20150007. PubMed PMID: 25849932.

92. Brunden KR, Zhang B, Carroll J, Yao Y, Potuzak JS, Hogan AM, Iba M, James MJ, Xie SX, Ballatore C, Smith AB, 3rd, Lee VM, Trojanowski JQ. Epothilone D improves microtubule density, axonal integrity, and cognition in a transgenic mouse model of tauopathy. The Journal of neuroscience : the official journal of the Society for Neuroscience. 2010;30(41):13861-6. doi: 10.1523/JNEUROSCI.3059-10.2010. PubMed PMID: 20943926; PMCID: 2958430. 
93. Zhang B, Maiti A, Shively S, Lakhani F, McDonald-Jones G, Bruce J, Lee EB, Xie SX, Joyce S, Li C, Toleikis PM, Lee VM, Trojanowski JQ. Microtubule-binding drugs offset tau sequestration by stabilizing microtubules and reversing fast axonal transport deficits in a tauopathy model. Proceedings of the National Academy of Sciences of the United States of America. 2005;102(1):227-31. doi: 10.1073/pnas.0406361102. PubMed PMID: 15615853; PMCID: 544048.

94. Zhang B, Carroll J, Trojanowski JQ, Yao Y, Iba M, Potuzak JS, Hogan AM, Xie SX, Ballatore C, Smith $A B, 3 r d$, Lee VM, Brunden KR. The microtubule-stabilizing agent, epothilone $D$, reduces axonal dysfunction, neurotoxicity, cognitive deficits, and Alzheimer-like pathology in an interventional study with aged tau transgenic mice. The Journal of neuroscience : the official journal of the Society for Neuroscience. 2012;32(11):3601-11. doi: 10.1523/JNEUROSCI.4922-11.2012. PubMed PMID: 22423084; PMCID: 3321513.

95. Hellal F, Hurtado A, Ruschel J, Flynn KC, Laskowski CJ, Umlauf M, Kapitein LC, Strikis D, Lemmon V, Bixby J, Hoogenraad CC, Bradke F. Microtubule stabilization reduces scarring and causes axon regeneration after spinal cord injury. Science. 2011;331(6019):928-31. doi: 10.1126/science.1201148. PubMed PMID: 21273450; PMCID: 3330754.

96. Sengottuvel V, Leibinger M, Pfreimer M, Andreadaki A, Fischer D. Taxol facilitates axon regeneration in the mature CNS. The Journal of neuroscience : the official journal of the Society for Neuroscience. 2011;31(7):2688-99. doi: 10.1523/JNEUROSCI.4885-10.2011. PubMed PMID: 21325537. 97. Baas PW, Ahmad FJ. Beyond taxol: microtubule-based treatment of disease and injury of the nervous system. Brain : a journal of neurology. 2013;136(Pt 10):2937-51. Epub 2013/07/03. doi: 10.1093/brain/awt153. PubMed PMID: 23811322; PMCID: Pmc3784279.

98. Bellouze S, Baillat G, Buttigieg D, de la Grange P, Rabouille C, Haase G. Stathmin 1/2-triggered microtubule loss mediates Golgi fragmentation in mutant SOD1 motor neurons. Mol Neurodegener. 2016;11(1):43. doi: 10.1186/s13024-016-0111-6. PubMed PMID: 27277231; PMCID: PMC4899909. 99. Smith R, Bacos K, Fedele V, Soulet D, Walz HA, Obermuller S, Lindqvist A, Bjorkqvist M, Klein P, Onnerfjord P, Brundin P, Mulder H, Li JY. Mutant huntingtin interacts with \{beta\}-tubulin and disrupts vesicular transport and insulin secretion. Human molecular genetics. 2009;18(20):3942-54. doi: 10.1093/hmg/ddp336. PubMed PMID: 19628478.

100. Freund RK, Gibson ES, Potter H, Dell'Acqua ML. Inhibition of the Motor Protein Eg5/Kinesin-5 in Amyloid beta-Mediated Impairment of Hippocampal Long-Term Potentiation and Dendritic Spine Loss. Mol Pharmacol. 2016;89(5):552-9. doi: 10.1124/mol.115.103085. PubMed PMID: 26957206.

101. Audouard E, Van Hees L, Suain V, Yilmaz Z, Poncelet L, Leroy K, Brion JP. Motor deficit in a tauopathy model is induced by disturbances of axonal transport leading to dying-back degeneration and denervation of neuromuscular junctions. Am J Pathol. 2015;185(10):2685-97. doi:

10.1016/j.ajpath.2015.06.011. PubMed PMID: 26272360.

102. Stevenson JW, Conaty EA, Walsh RB, Poidomani PJ, Samoriski CM, Scollins BJ, DeGiorgis JA. The Amyloid Precursor Protein of Alzheimer's Disease Clusters at the Organelle/Microtubule Interface on Organelles that Bind Microtubules in an ATP Dependent Manner. PloS one. 2016;11(1):e0147808. doi: 10.1371/journal.pone.0147808. PubMed PMID: 26814888; PMCID: PMC4729464.

103. Gan KJ, Morihara T, Silverman MA. Atlas stumbled: kinesin light chain-1 variant E triggers a vicious cycle of axonal transport disruption and amyloid-beta generation in Alzheimer's disease. Bioessays. 2015;37(2):131-41. doi: 10.1002/bies.201400131. PubMed PMID: 25394182. 


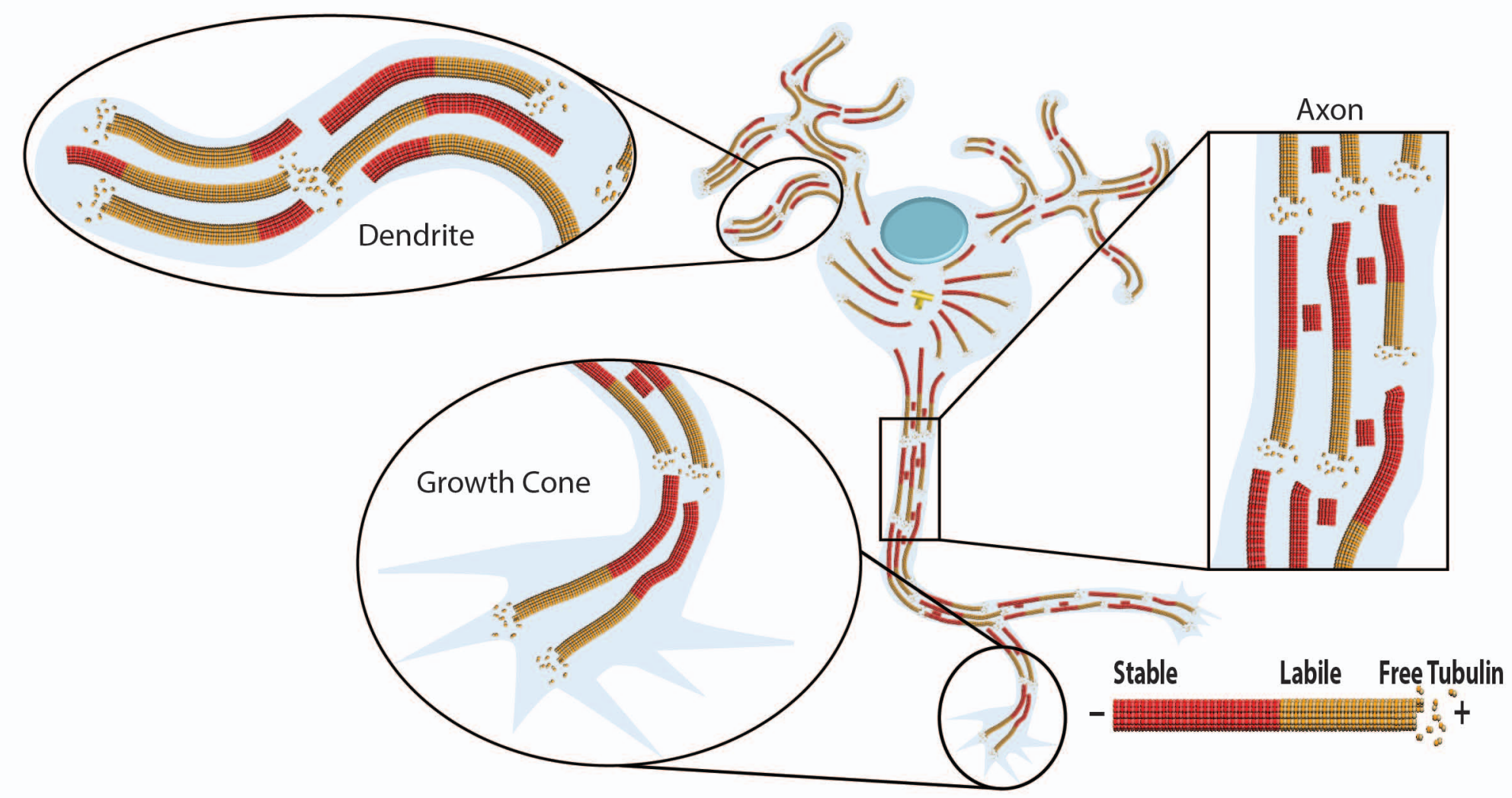


\begin{tabular}{|l|l|}
\hline A & B \\
\hline
\end{tabular}

Normal Axonal Microtubules

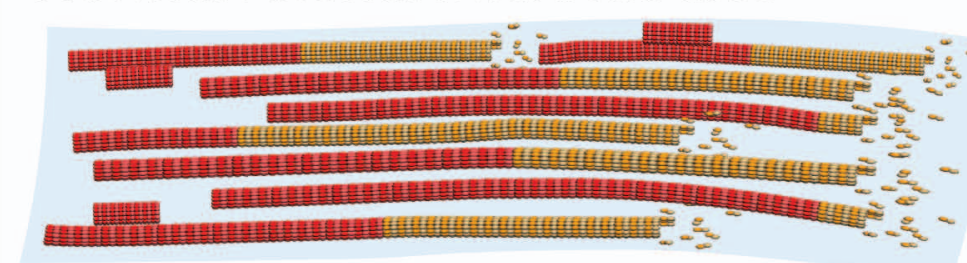

C

Loss of Labile Microtubule Mass

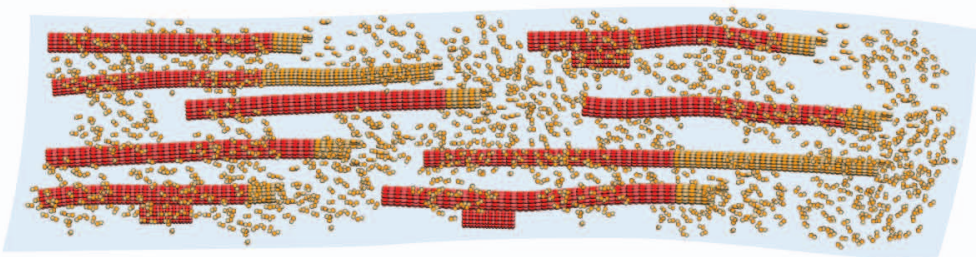

Microtubule Destabilization

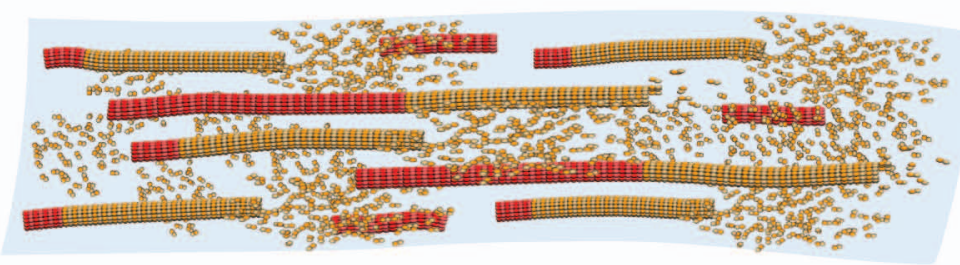

D

Abnormal Severing of Microtubules

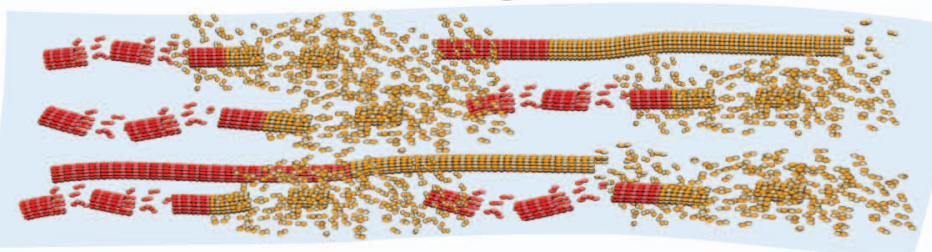

$\mathbf{E}$

Normal Microtubule Transport of Vesicles and Mitochondria

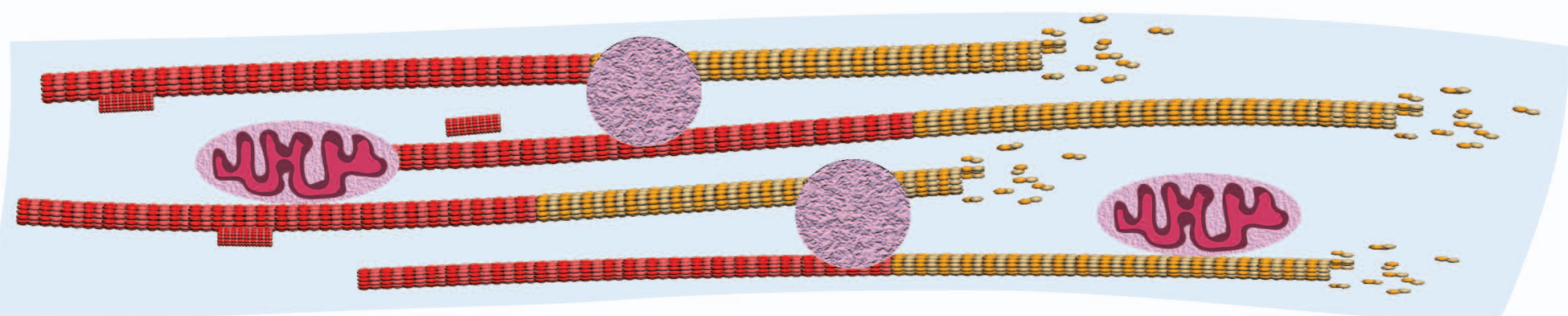

Impaired Microtubule Transport of Vesicles and Mitochondria

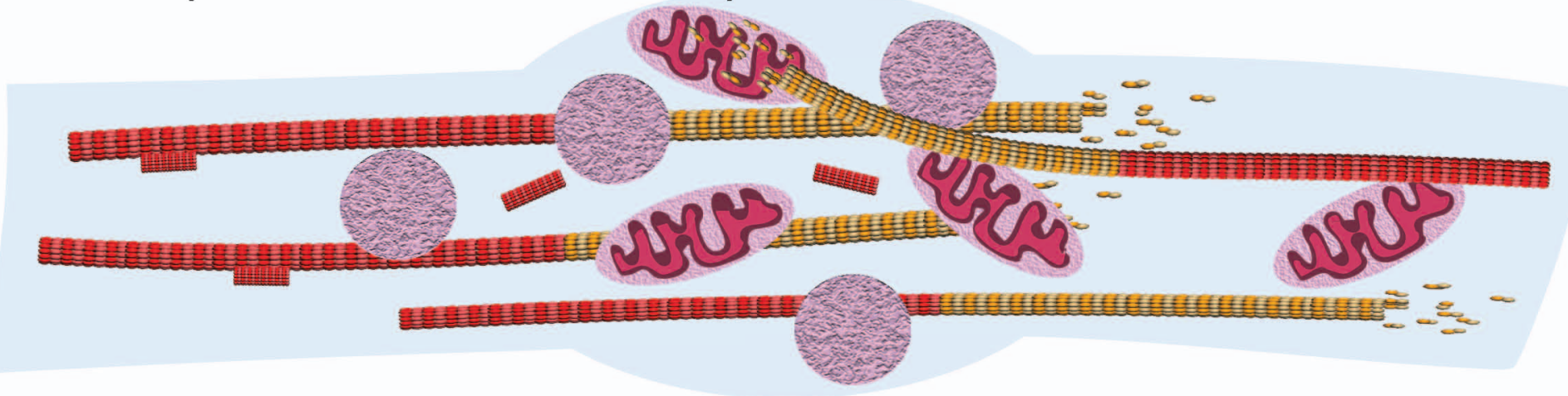

